\title{
The Correlation of Oral Mucosa Lesions with Dermatological Preliminary Diagnosis and Epidemiological Properties
}

\author{
Müge Özçelik Korkmaz' ${ }^{1}$ Bahar Sevimli Dikicier², Necati İlhan ${ }^{1}$, Mehmet Güven ${ }^{1}$ \\ 1: Sakarya University Medical Faculty Otolaryngology Department \\ 2: Sakarya University Medical Faculty Dermatology Department \\ Müge Özçelik, ORCID: 0000-0003-4726-7987 \\ Bahar Sevimli Dikicier, ORCID:0000-0002-1912-3946 \\ Necati İlhan, ORCID:0000-0002-5832-920X \\ MehmetGüven, ORCID: 0000-0002-3665-2428
}

\begin{abstract}
Objective: Our study aims to determine the prevalence and distribution characteristics of oral mucosal lesions $(\mathrm{OML})$, which are frequently encountered in clinical practice, and determine the correlation between dermatological pre-diagnoses and definite histopathological diagnoses.
\end{abstract}

Methods: The clinical data of 361 individuals who were consulted by Dermatology to the Otolaryngology Clinic of Sakarya University Faculty of Medicine Training and Research Hospital for oral mucosal lesions and underwent excision biopsy were included in the study. Each patient's data, such as gender, age, and smoking history, were scanned and recorded. Regarding the lesions, localization of the lesions, duration of their presence, clinical pre-diagnoses, and definite diagnoses were recorded. Accordingly, the diagnostic distribution characteristics of the lesions and the correlation between diagnoses were evaluated.

Results: When the age and gender distribution of the patients included in the study were examined, 152 (42.1\%) were male, and $209(57.9 \%)$ were female. The average age was $49.72 \pm 1.21$. While 134 patients $(57,37,1 \%)$ were $\geq 65$ years old, 227 patients $(62,9 \%)$ were under 65 years old. $185(51.2 \%)$ of the lesions were localized in the buccal mucosa. The most common ones were chronic inflammatory lesions $(21.1 \%)$ and lesions of traumatic origin (13.3\%). A statistically significant correlation was observed between clinical presuppositions and definite histopathological diagnoses $(p<0.05)$. When we evaluated histopathological diagnoses according to gender and age distribution, no difference was observed in gender distribution. At the same time, premalignant and malignant lesions were statistically significantly higher in elderly individuals (65 years and over) seen. In terms of smoking habits, it was seen that smoking was significantly associated with premalignant and malignant diseases $(p<0.05)$.

Conclusion: This study on oral mucosal lesions, which concern a significant part of the society, will be critical in terms of its contribution to epidemiological data as well as evaluating the reliability of preliminary dermatological diagnoses.

Keywords: Oral mucosal lesion, epidemiology, prevalance, precancerous lesions, Turkey
Correspondence: Müge Özçelik Korkmaz

Department of Otorhinolaryngology, Sakarya University Training and Research Hospital, Sakarya, Türkiye

E-mail: ozcelikmuge@gmail.com
Online available at: www.entupdatesjournal.org

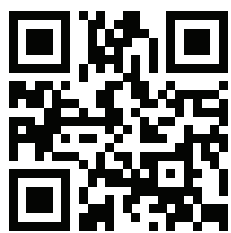




\section{Introduction}

The oral cavity consists of the gingiva, retromolar area, cheek and palate mucosa, floor of the mouth, and lips. Morphological and histopathological applications in the mucosa lining the oral cavity, which may present with different pathologies. ${ }^{[1]}$ Its prevalence in the adult population has been reported in the literature, with $10.8 \%-81.3 \%$ in oral mucosal lesions (OML) in the literature. ${ }^{[2,3]}$ All these lesions in the oral mucosa may be the harbinger of a malignant process or occur in a secondary systemic involvement. Therefore, its diagnosis and treatment are of great importance in clinical practice.

Most OML has a multifactorial etiology. These may include systemic diseases, drugs used, metabolic pants, and nutritional deficiencies. ${ }^{[5]}$ Moreover, the oral mucosa condition is also affected by localities: mechanical trauma (oral mucosa biting habit, denture or dental filling), thermal trauma, natural and surface biofilm, saliva content, and amount secreted nicotine addiction and alcohol dependence. ${ }^{[6,7]}$ age and sex can be a significant factor in the frequency of lesions. It is noteworthy that benign lesions are more common in young adults, and oral mucosal diseases are candidiasis, lichen planus, leukoplakia, traumatic lesions, and recurrent aphthous stomatitis. ${ }^{[8,9]}$ Although inflammatory lesions are prominent in the adult age group, it should be kept in mind that there may be an underlying malignant process. The gold standard in the diagnosis of OML is to confirm the diagnosis with histopathological examination. ${ }^{[10]}$

Epidemiological studies on this subject provide essential information to understand the prevalence, incidence, and severity of OML in the population. However, studies on this subject with precise histopathological data are scarce. In particular, studies have been made on this issue in Turkey is generally made evaluating the initial inspection data of early lesions. ${ }^{[11,12]}$ To determine the incidence of oral mucosal disease in more significant numbers made with accurate diagnostic results shows that there is a need to work.

In clinical practice, it is seen that most of the patients due to OML are evaluated by dermatology or dentists in the first place. However, patients are referred to otolaryngology clinics to confirm the diagnosis and/or treat prolonged lesions. In this way, the patients' follow-up and treatment approaches can be determined by finalizing the diagnoses in OML. However, it becomes essential to evaluate the correlation and reliability of diagnostics between clinics. Therefore, in our study, we aimed to evaluate the demographic distribution characteristics, its relations with possible etiological factors, and its correlation with dermatological pre-diagnoses and the final diagnosis of the patients who underwent excision and biopsy for OML.

\section{Materials and Methods}

In this study, we analyzed the medical records of $439 \mathrm{pa}-$ tients referred from Sakarya University Dermatology Department and underwent excision or biopsy of oral mucosal lesions that exist longer than three months in the otolaryngology clinic between January 2015 and June 2020. The ethical approval of the study was obtained from the ethics committee of Sakarya University Medical Faculty $(715224473 / 050.01 .04)$

Records of age, gender, and smoking information of each patient were examined and recorded. The lesion's duration, localization, pre-diagnosis, and histopathological diagnosis data were scanned and recorded. Patients who did not have preliminary diagnosis information provided by the dermatology and knowledge of histopathological diagnosis were not included in the study. World Health Organization (WHO) guidelines (2013) for adults were used in the methodological procedure of oral examination and the description of OMLs. ${ }^{[13]}$ Again, only the borders of the oral mucosa; labial mucosa and sulcus, buccal mucosa and sulcus, gingiva and alveolar ridge, floor of the mouth, and soft and hard palate. Tongue lesion and biopsy samples were not included in the study.

In order to compare the clinical pre-diagnoses and histopathological diagnoses, the evaluation was made by generally dividing into eight subgroups considering the etiological reasons and clinical features. According to this, traumatic or other benign lesions (fibroma, granuloma, fibroepithelial polyp, pyogenic lesions, peripheral giant 
cell granuloma, papilloma, hemangiomas), lichen planus, chronic inflamatuar lesions (hyperkeratosis, parakeratosis, acanthosis, pseudoseitheliomatous hyperplasia), other premalignant lesions (leukoplakia, eukoplakia), gland-derived lesions (mucocele, cyst, pleomorphic adenoma, adenoid cystic carcinoma, myoepitelyoma) pemphigus vulgaris, malignant lesions (Oral squamous cell carcinoma, verrucous carcinoma, mucosal melanoma,kaposi sarcoma, ewing sarcoma) and other rare pathologies.

Preoperative clinical diagnosis and postoperative histopathological diagnoses of the patients were evaluated in terms of correlation. If there was more than one pre-diagnosis in preliminary dermatological diagnosis, a correlation was accepted if it matches one of them. The patients were grouped according to their gender and age distribution as $18-24,25-34,35-44,45-54.55-64,65-74$, and over 74 years old. As etiological factors, they were grouped as smokers, nonsmokers, and ex-smokers according to smoking history. The distribution characteristics of histopathological diagnoses among these categories were evaluated comparatively.

\section{Statistical Analysis}

We used descriptive statistics, such as mean (SD) and distribution for the analysis of patients' characteristics. The categorical data were provided as numbers (n) and percentages (\%). The Kolmogorov - Smirnov test was performed for the normality distribution analysis, whereas the nonparametric tests were conducted according to the results. The categorical variables were compared by the pearson chisquare or fisher-exact test. In addition, $\mathrm{p}$ values less than 0.05 were accepted as significant. All the statistical analyzes were performed by using the commercial software (IBM SPSS Statistics.Version 23.0. Armonk. NY: IBM Corp.)

\section{Results}

A total of 78 patients who did not meet the study criteria were excluded from the study. The descriptive data of 361 patients included in the study is shown at Table 1 . The total number of male patients was 152 (42.1\%), whereas the number of female patients was 209 (57.9\%). The over-

\begin{tabular}{|c|c|}
\hline Paramaters & \\
\hline \multicolumn{2}{|l|}{ Gender (n/\%) } \\
\hline Male & $152(42.1)$ \\
\hline Female & 209 (57.9) \\
\hline Mean Age (Years) & $48.22 \pm 18.20$ \\
\hline \multicolumn{2}{|l|}{ Age Groups (n/\%) } \\
\hline $18-24$ & $45(12.4)$ \\
\hline $25-34$ & 49 (13.5) \\
\hline $35-44$ & $45(12.4)$ \\
\hline $45-54$ & $94(26)$ \\
\hline $55-64$ & $57(15.7)$ \\
\hline $65-74$ & 49 (13.5) \\
\hline $75<$ & $22(6)$ \\
\hline \multicolumn{2}{|c|}{ Smoking Status ( $\mathrm{n} / \%)$} \\
\hline Smokers & $133(36,9)$ \\
\hline Non-smokers & $154(42,6)$ \\
\hline Ex-smokers & $74(20,5)$ \\
\hline
\end{tabular}

all mean age of the patients was $48.22 \pm 18.20$ years (min 18 - max 92). 134 patients $(57,37,1 \%)$ were $\geq 65$ years old, 227 patients $(62,9 \%)$ were younger than 65 years old. The mean age was $49.72 \pm 1.21$. When the patients are divided according to age ranges, 45 (12.4\%) people between the ages of $18-24,49(13.5 \%)$ people between the ages of $25-24,45$ (12.4\%) between the ages of 35-44, 94 (26\%) between the ages of 45-54, There were 57 (15.7\%) people between the ages of 55-64, 49 (13.5\%) between 65-74, and $22(6 \%)$ people who were 75 and over. There was no statistically significant difference between the female and male patients in terms of age distribution ( $p>0.05$ ). While the rates of smokers, non-smokers and ex smokers in males were $52 \%, 28 \%$ and $20 \%$, respectively, these rates were $26 \%, 53 \%$ and $21 \%$ in females. The mean duration of the lesions was $8.32 \pm 9.62$ months.

The localization, histopathological definite diagnosis and clinical pre-diagnosis data of the cases are given in Table 2. When looking at the distribution of lesions according to localization, 185 (51.2\%) of the lesions are from the buccal mucosa, 82 (22.7\%) from the labial mucosa, 36 $(9.9 \%)$ from the gingiva and alveolar ridge $32(8.8 \%)$ floor of the mouth Of the, and $22(6,1 \%)$ soft and hard palates, 4 
Table 2. Distribution of lesions by histopathologic diagnosis and age groups.

\begin{tabular}{|c|c|c|c|c|c|c|c|c|}
\hline \multirow{2}{*}{ TRAUMATIC LESIONS } & \multicolumn{7}{|c|}{ Age Groups } & \multirow{2}{*}{ TOTAL } \\
\hline & $18-24$ & $25-34$ & $35-44$ & $45-54$ & $55-64$ & $65-74$ & $75+$ & \\
\hline Fibroma & 1 & 4 & 10 & 11 & 7 & 6 & 1 & 40 \\
\hline Granuloma & 2 & 0 & 2 & 5 & 4 & 3 & 1 & 17 \\
\hline Fibroepithelial polyp & 1 & 1 & 3 & 4 & 2 & 3 & 0 & 14 \\
\hline Pyojenic lesions & 0 & 0 & 0 & 0 & 0 & 3 & 0 & 3 \\
\hline Peripheric giant cell granuloma & 0 & 0 & 3 & 0 & 0 & 0 & 0 & 3 \\
\hline \multicolumn{9}{|l|}{ OTHER BENIGN LESIONS } \\
\hline Papilloma & 13 & 14 & 9 & 9 & 3 & 5 & 0 & 53 \\
\hline Hemangiomas & 0 & 2 & 2 & 0 & 3 & 0 & 0 & 7 \\
\hline TOTAL & 17 & 21 & 29 & 29 & 19 & 20 & 2 & 137 \\
\hline LICHEN PLANUS & 0 & 6 & 4 & 8 & 10 & 12 & 1 & 41 \\
\hline \multicolumn{9}{|c|}{ PREMALIGN LESIONS EXCEPT LICHEN PLANUS } \\
\hline Leukoplakia & 0 & 0 & 0 & 7 & 1 & 2 & 4 & 14 \\
\hline Erythroplakia & 0 & 0 & 0 & 2 & 1 & 2 & 1 & 6 \\
\hline Dysplasia & 0 & 1 & 2 & 5 & 3 & 1 & 3 & 15 \\
\hline TOTAL & 0 & 1 & 2 & 14 & 5 & 4 & 8 & 34 \\
\hline \multicolumn{9}{|l|}{ CHRONIC INFLAMATION } \\
\hline Hyperkeratosis & 1 & 1 & 1 & 2 & 3 & 4 & 0 & 12 \\
\hline Parakeratosis & 0 & 1 & 1 & 4 & 1 & 3 & 1 & 11 \\
\hline Acanthosis & 1 & 3 & 2 & 8 & 6 & 6 & 2 & 28 \\
\hline Pseudoepitheliomatous hyperplasia & 0 & 2 & 3 & 6 & 2 & 2 & 0 & 15 \\
\hline TOTAL & 2 & 7 & 7 & 20 & 14 & 11 & 3 & 64 \\
\hline \multicolumn{9}{|l|}{ GLAND DERIVATED LESIONS } \\
\hline Mucosel & 8 & 5 & 1 & 1 & 0 & 0 & 0 & 15 \\
\hline Cyst/ranula & 9 & 3 & 0 & 4 & 1 & 0 & 0 & 17 \\
\hline Pleomorphic Adenoma & 0 & 0 & 0 & 2 & 0 & 1 & 1 & 4 \\
\hline TOTAL & 17 & 8 & 1 & 7 & 1 & 1 & 1 & 36 \\
\hline PEMPHIGUS VULGARIS & 0 & 0 & 0 & 4 & 4 & 4 & 3 & 15 \\
\hline \multicolumn{9}{|l|}{ MALIGN LESIONS } \\
\hline Squamos cell carcinoma & 0 & 0 & 2 & 9 & 6 & 1 & 3 & 21 \\
\hline Verrüköz Carcinoma & 0 & 0 & 0 & 1 & 0 & 0 & 0 & 1 \\
\hline Malign Melanoma & 0 & 0 & 0 & 0 & 1 & 0 & 0 & 1 \\
\hline Ewing /kaposi sarcoma & 0 & 0 & 1 & 1 & 1 & 0 & 0 & 3 \\
\hline TOTAL & 0 & 0 & 2 & 10 & 7 & 1 & 3 & 25 \\
\hline OTHERS & 0 & 0 & 1 & 2 & 2 & 2 & 2 & 9 \\
\hline
\end{tabular}


$(1,1 \%)$ were located retromolar trigone (Figure 1). There was no statistically significant difference between gender and age groups in terms of location distribution of lesions ( $\mathrm{p}>0.05)$.

Data on the distribution of diagnoses are given in Table 2. It was observed that the pre-diagnoses were usually grouped into certain groups. Accordingly, the most common pre-diagnoses were contact dermatitis (19.2\%), lichen planus(18.1\%), granuloma (16.7\%) squamous cell carcinoma (14.8\%), leukoplakia(11.4\%), papilloma(7,6\%), pemfigus(6,6\%), mucocel(5.6\%), respectively. In terms of histopathological distributions, the most common were traumatic and benign lesions (37.9\%), chronic inflamatuar lesions $(17.7 \%)$ lichen planus (11.3\%), respectively. When the pre-diagnosis and histopathological diagnosis data were evaluated, it was seen that the pre-diagnoses were generally grouped in a similar way. When the pre-diagnosis and histopathological diagnosis correlations of the lesions were examined, it was seen that the results were statistically significantly correlated for each diagnosis group. $(\mathrm{P}<0.05)$ The diagnoses with the highest correlation were malignant, premalignant lesions and lichen planus, respectively.
The number of rare pathologies that were not categorized in any group was $9(2.4 \%)$ and these lesions were as follows; epilus fissuratum, melanotic lesions, amiloidosis, lenfoma,epidermal cyst.

There was no significant difference in the distribution of histopathological diagnoses between genders. $(p=0.22)$ In terms of age distribution, there was a statistically significant increase in the rate of premalignant and malignant lesions in the patient group aged 65 years and over. There was no statistically significant difference in the distribution of histopathological diagnoses among other age groups.

In terms of smoking, there was a statistically significant correlation between precancerous lesions, malignant lesions and lichen planus regardless of gender in active smokers $(\mathrm{p}<0.05)$. There was no relationship with a certain diagnostic group in those who quit smoking and those who did not smoke. (Table 3)

\section{Discussion}

Different rates have been reported in studies conducted in different populations on the prevalence of oral mucosal lesions. ${ }^{[3,14]}$ Generally, it can be said that the incidence of

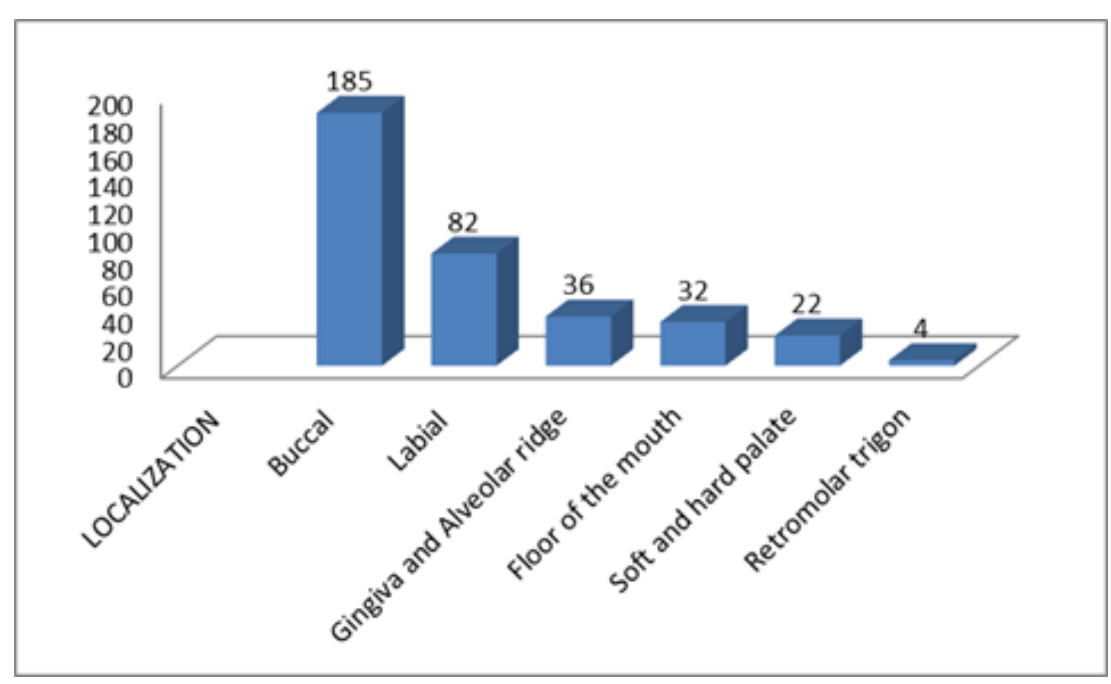

Figure 1. Distribution of lesions by localization 


\begin{tabular}{|c|c|c|c|c|}
\hline \multicolumn{5}{|c|}{ Smoking Status } \\
\hline $\begin{array}{l}\text { Histopathologic } \\
\text { Groups (n) }\end{array}$ & Smokers & $\begin{array}{c}\text { Non- } \\
\text { Smokers }\end{array}$ & Ex-smokers & $P^{*}$ \\
\hline $1(n=137)$ & 44 & 64 & 29 & 0.32 \\
\hline $2(n=41)$ & 22 & 11 & 8 & 0.02 \\
\hline $3(n=34)$ & 18 & 8 & 8 & 0.01 \\
\hline $4(n=64)$ & 18 & 37 & 9 & 0.54 \\
\hline $5(n=36)$ & 11 & 17 & 8 & 0.43 \\
\hline $6(n=15)$ & 5 & 7 & 3 & 0.63 \\
\hline $7(n=25)$ & 13 & 5 & 7 & 0.04 \\
\hline $8(n=9)$ & 2 & 5 & 2 & 0.08 \\
\hline Total & 133 & 154 & 74 & \\
\hline \multicolumn{5}{|c|}{$\begin{array}{l}\text { 1: Traumaticlbenign lesions 2:Lichen planuus 3: Premalign lesions } \\
\text { 4: Chronic inflamatuar lesions 5: Gland derivated lesions } \\
\text { 6: Pemphigus vulgaris 7: Malign Lesions 8: Others } \\
\text { *: Pearson chi-square or fisher-exact test }\end{array}$} \\
\hline
\end{tabular}

OML's is increasing in the adult age group. In the studies made for the distribution of the different assessments and studies based on impedance from Turkey, although histopathologic diagnosis was used different methods of categorizing it is rare. ${ }^{[15]}$ In this respect, the important point of our study is the verification of clinical pre-diagnoses with definite diagnoses and their reliability. Considering the results of the study, it is seen that the correlation between the diagnoses was statistically significant.

Considering the frequency distribution of lesions in our study, it is noteworthy that the most common pre-diagnosis and histopathological diagnosis are traumatic and benign lesions. Similarly, when the literature was reviewed on this subject, it was seen that the majority of pathologies developed from traumatic etiology underlying OML consisted of pathologies. Considering the role of tooth and prosthetic lesions in the etiology of OML, this frequency was at the expected level in our study evaluating the results of the adult population. ${ }^{[16,17]}$ The second most common lesions were chronic inflamatuar lesions such as acanthosis, keratosis. ${ }^{[18]}$ In studies conducted by most dentists, it is stated that lesions associated with excessive melanin pigmentation are the most common pathology of the oral mucosa. ${ }^{[17,19]}$ However, the evaluation results of these studies were made based on clinical pre-diagnoses. In our study, detailed diagnostic classification of chronic inflammatory lesions was made with diagnoses confirmed histopathologically as well as clinical pre-diagnoses.

One of the most common chronic inflammatory lesions in our study was pseudoepitheliomatous hyperplasia $(9.7 \%)$, which is an outstanding histopathological diagnosis. Pseudoepitheliomatous hyperplasia can resemble epithelial tumors, especially squamous cell carcinoma, due to its histological appearance and is included in differential diagnoses. ${ }^{[2]}$ Due to similarity, the difficulty in distinguishing oral mucosa malignant lesions from pseudoepitheliomatous hyperplasia may lead to late diagnosis of malignancies. $^{[21]}$ Therefore, differential diagnosis should be made with caution in chronic inflammatory lesions. Another common diagnosis was lichen planus (17.2\%). It has been reported that oral symptoms of lichen planus may develop weeks or months before skin lesions, and even skin lesions may not occur. The fact that the premalignant potential of oral lichen planus cases, which is controversial, has been shown in recent studies, increases the lichen planus. ${ }^{[22,23]}$

Although the most common diagnostic finding is squamous cell carcinoma among malignant pathologies, adenocystic carcinoma was the second most common malignancy originating from the salivary gland. Salivary gland tumors should be kept in mind, especially in long-term, asymptomatic, smooth-surfaced hard oral mucosal lesions. Again, rarely, there were sarcoma cases among malignant pathologies. Therefore, it should be kept in mind that it may be seen in bone-origin malignancies such as sarcoma in the oral cavity. Again, only one case was found to be diagnosed with mucosal melanoma. In this respect, the rate of malignant lesions of our results was consistent with the literature findings. ${ }^{[24]}$

In terms of localization of the lesions, it is noteworthy that the most common localization area is the buccal mucosa $(51.2 \%)$. The most common lesions in this area were 
chronic inflammatory lesions and lichen planus. In this respect, there was a statistically significant difference compared to other parts. There was no significant difference in the localization distribution of other diagnoses. This appears to be a natural consequence, considering that the most common causes, such as teeth, dentures, and biting, are in the etiology of chronic inflammatory lesions. Again, in this region, the correlation value between diagnoses was statistically significantly high. In some studies in the literature, the hard palate has been defined as the most common site of lesions. However, lesions in this area are mostly mucosal color changes due to nicotine use. ${ }^{[25,26]}$

Studies indicate that the prevalence of oral mucosal diseases is higher in elderly individuals than young adults and shows the relationship between OMLs and aging. ${ }^{[27]}$ In our study, $62 \%$ of the cases were under 65 years old. In terms of age distribution, the age range of 45-54 was the largest age group (26\%). Referring to other studies from Turkey was seen as similar to the results. ${ }^{[11,14]}$ In general, there was no significant difference in the distribution of diagnoses among age groups. It was found that the incidence of only premalignant and malignant lesions was higher in individuals over 65 years of age, in accordance with the literature. ${ }^{[26,27]}$ In other age groups, the most common lesions were ulcerative lesions, followed by lichen planus. In our study group, no significant difference was found between genders in terms of lesion distribution. In the study by Mumcu et al., from Turkey, in which they evaluated patients who applied to the dentistry faculty for OML, no significant difference was found between the female/male ratio. ${ }^{[12]}$ However, in their study from Slovenia, Kansky et al. stated that OMLs do not differ in terms of gender distribution in society. ${ }^{[28]}$

It is a known fact that smoking increases the incidence of OML. In our study group, the rate of smoking, both active and in the past years, was observed to be relatively high (74\%). A significant relationship was found between smoking and especially the incidence of chronic inflammatory and precancerous lesions. The results of many epidemiological studies conducted around the world also support our findings. ${ }^{[29,30]}$ However, only accessing information about smoking from the records was the missing point of our study. Questioning and evaluating other possible etiological causes such as dental trauma and prosthesis will make the studies more substantial. Our study findings, while leukoplakia (8.2\%) was the most common in the precancerous lesion group, erythroplakia (1.1\%) was rare. Considering the general data, it is seen that the most common lesion among precancerous lesions is leukoplakia. A retrospective study of 15,811 US individuals showed that risk factors for oral leukoplakia include male sex. Other risk factors include cigarette or pipe/cigar use, smokeless-tobacco use, regular alcohol consumption, and diabetes. ${ }^{[3]]}$ In studies conducted from different countries, the most common age group for oral leukoplakia was stated as the age group of 40-60. ${ }^{[32,33]}$ In our study group, the features of precancerous lesions were found to be expected in the group aged 60 and above, but there was no difference in terms of gender distribution.

As is known, OML is a pathology that involves more than one clinic, such as family physicians, dentistry, dermatology, and otolaryngology. Most of the time, patients are directed to ear, nose, and throat clinics for biopsy. However, evaluating the accuracy of the pre-diagnoses with histopathological results is very important in clinical practice. For this purpose, we included patients who were pre-evaluated in the dermatology clinic in the study group. Considering our study results, we found that the correlation between clinical pre-diagnoses and definite diagnoses was statistically significantly high. Besides, having results for definite diagnoses is very valuable in terms of prevalence and epidemiological information. Future studies conducted with more extensive series and evaluating the etiological factors will provide more information on this subject.

\section{Acknowledgments: None}

Ethics Committee Approval: The study protocol was approved by the local ethics committee (715224473/050.01.04)

Informed Consent: Written informed consent was 
obtained from the patients who had participated in this study.

Author Contributions: Designing the study - M.O.K, B.S.D., N.İ., M.G Collecting the data - M.O.K, B.S.D., N.I; Analysing the data - M.O.K ; Writing the manuscript - M.O.K, B.S.D.,N.İ, M.G; Confirming the accuracy of the data and the analyses - M.O.K, B.S.D.,N.İ, M.G.

\section{References}

1. B W Neville, C. M. Allen, and A. C. Chi, Oral and Maxillofacial Pathology. In: Elsevier, St. Louis, MO, USA, 4th edition, 2016.

2. Fierro-Garibay C, Almendros-Marqués N, Berini-Aytés L, Gay-Escoda C. Prevalence of biopsied oral lesions in a Department of Oral Surgery. J Clin Exp Dent 2011;3:73-7.

3. Kovac-Kovacic M, Skaleric U. The prevalence of oral mucosal lesions in a population in Ljubljana, Slovenia. J Oral Pathol Med 2000;29:331-5.

4. Kramer IH, Pindborg JJ, Bezroukov V, Inferri JS. Guide to epidemiology and diagnosis of oral mucosal diseases and conditions. World Health Organization, Community Dentistry and Oral Epidemiology, vol. 8, no. 1,pp. $1-26,1980$.

5. Greer R, Marx R, Said S, Prok L. Pediatric Head, and Neck Pathology. Cambridge, United Kingdom: Cambridge University Press; 2017:77-99.

6. Harris CK, Warnakulasuriya KA, Cooper DJ, Peters TJ, Gelbier S. Prevalence of oral mucosal lesions in alcohol misusers in South London. J Oral Pathol Med 2004;33:253-9.

7. Martori E, Ayuso-Montero R, Martinez-Gomis J, Vi-as M, Peraire M. Risk factors for denture-related oral mucosal lesions in a geriatric population. $\mathrm{J}$ Prosthet Dent 2014;111:273-9.

8. Reichart PA. Oral mucosal lesions in a representative cross-sectional study of aging Germans. Community .Dent Oral Epidemiol 2000;28:390-8.

9. Cebeci AR, Gülşahı A, Kamburoğlu K, Orhan K, Öztaş B. Prevalence and distribution of oral mucosal lesions in an adult turkish populatioMed Oral Patol Oral Cir Bucal 2009;14:272-7.

10. Allon I, Kaplan I, Gal G, Chaushu G, Allon DM. The clinical characteristics of benign oral mucosal tumors. Med Oral Patol Oral Cir Bucal 2014;19:438-43.

11. Dundar N, Ilhan Kal B. Oral mucosal conditions and risk factors among elderly in a Turkish school of dentistry. Gerontology 2007;53:165-72.

12. MumcuG, Cimilli H, Sur H, Hayran O, Atalay T. Prevalence and distribution of oral lesions: a cross-sectional study in Turkey. Oral Diseases 2005;11:81-7.

13. World Health Organisation. Oral health surveys: basic methods, 5th edn. 2013: World Health Organisation: Geneva
Conflict of Interest: The authors have no conflicts of interest to declare.

Financial Disclosure: The authors declare that this study has not received any financial support.

14. Beata GłowackaB, Tomasz Konopka A . Prevalence of oral mucosal lesions in young seniors in the Wrocław region. Dent Med Probl 2018;55:405-10

15. Gunes A,Karali E, Sebit T. Retrospective analysis of benign and premalign lesions in the oral cavity. Mucosa 2019;2:48-52.

16. Saraswathi TR, Ranganathan K, Shanmugam S, Sowmya R,Narasimhan PD, Gunaseelan R. Prevalence of oral lesions in relation to habits: Cross-sectional study in South India. Indian J Dent Res 2006;17:121-5.

17. Rivera C, Droguett D, Arenas-Márquez MJ. Oral mucosal lesions in a Chilean elderly population: A retrospective study with a systemic review from thirteen countries. J Clin Exp Dent 2017;9:276-83.

18. Ercalik-Yalcinkaya S, Özcan M. Association between Oral Mucosal Lesions and Hygiene Habits in a Population of Re-movable Prosthesis Wearers. J Prosthodont 2015;24:271-8.

19. Gambhir RS, Veeresha KL, Sohi R, et al. The prevalence of oral mucosal lesions in the patients visiting a dental school in Northern India in relation to sex, site and distribution: a retrospective study. J Clin Exp Dent 2011;3 10-7.

20. Nayak VN, Uma K, Girish HC, Murgod S, Shyamala K, Naik RB. Pseudoepitheliomatous hyperplasia in oral lesions: A review. J Int Oral Health 2015;7:148-52.

21. Price A, Miller JH, Junkins-Hopkins JM. Pseudocarcinomatous hyperplasia in anaplastic large cell lymphoma, a mimicker of poorly differentiated squamous cell carcinoma: Report of a case and review of the literature. J Cutan Pathol 2015;42:863-9.

22. De Rossi SS, Ciarrocca K. Oral lichen planus and lichenoid mucositis. Dent Clin North Am 2014;58:299-313.

23. Aghbari SMH, Abushouk AI, Attia A, et al. Malignant transformation of oral lichen planus and oral lichenoid lesions: a meta-analysis of $20095 \mathrm{pa}-$ tient data. Oral Oncol 2017;68:92-102.

24. Maymone MB, Greer RO, Burdine LK, et al .Benign oral mucosal lesions: Clinical and pathological findings. J Am Acad Dermatol 2019;81:43-56.

25. Bhatnagar P, Rai S, Bhatnagar G, et al. Prevalence study of oral mucosal lesions, mucosal variants, and treatment required for patients reporting to a dental school in North India: In accordance with WHO guidelines. J Family Community Med 2013;20:41-8. 
26. Riaz N, Warraich RA. Tumors and tumor like lesions of the orofacial region at Mayo Hospital, Lahore five year study. Annals of KEMU 2011;17:123-6.

27. Pai A, Deverashetty A. Changing Trends in the Oral Mucosa of Geriatric Population - An Epidemiological Study. J Indian Acad Geriatr 2017;13:10-7

28. Kansky AA, Didanovic V, Dovsak T, Brzak BL, Pelivan I, Terlevic D. Epidemiology of oral mucosal lesions in Slovenia. Radiol Oncol 2018; 52:263-6.

29. Verma S, Sharma H. Prevalence of Oral mucosal lesions and their associa-tion with Pattern of tobacco use among patients visiting a dental institution. Indian J Dent Res 2019;30:652-5.
30. Behura SS, Masthan MK, Narayanasamy AB. Oral Mucosal Lesions Associated with Smokers and Chewers - A Case-Control Study in Chennai Population. J Clin Diagn Res 2015;9:17-22.

31. Lodi G, Franchini R, Warnakulasuriya S, et al. Interventions for treating oral leukoplakia to prevent oral cancer. Cochrane Database Syst Rev 2016; 7:CD001829.

32. Holmstrup P, Dabelsteen E. Oral leukoplaki ad to treat or not to treat. Oral Dis 2016;22:494-7.

33. Yardimci G, Kutlubay Z, Engin B, Tuzun Y. Precancerous lesions of oral mucosa. World J Clin Cases 2014;2:866-72.

This is an open access article distributed under the terms of the Creative Commons Attribution-NonCommercial-NoDerivs 3.0 Unported (CC BY- NC-ND3.0) Licence (http://creativecommons.org/licenses/by-nc-nd/3.0/) which permits unrestricted noncommercial use, distribution, and reproduction in any medium, provided the original work is properly cited.

Please cite this article as: Özçelik Korkmaz M., Sevimli Dikicier B., İlhan N., Güven M. The Correlation of Oral Mucosa Lesions with Dermatological Preliminary Diagnosis and Epidemiological Properties. ENT Updates 2020;10(3): 409-417 